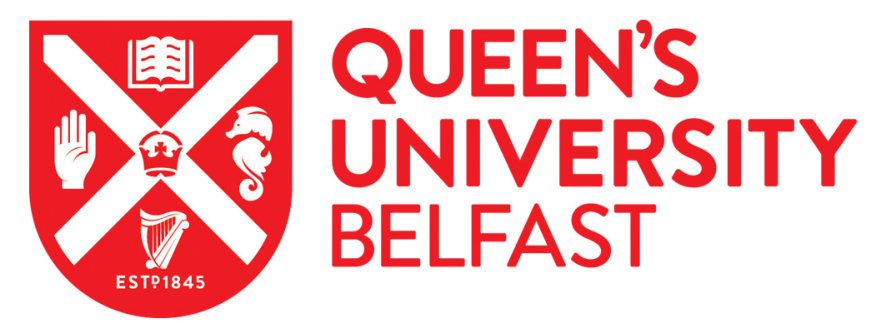

\title{
Acid-labile protein-adducted heterocyclic aromatic amines in human blood are not viable biomarkers of dietary exposure: A systematic
} study.

Cooper, K. M., Brennan, S. F., Woodside, J. V., Cantwell, M., Guo, X., Mooney, M., Elliott, C. T., \& Cuskelly, G. J. (2016). Acid-labile protein-adducted heterocyclic aromatic amines in human blood are not viable biomarkers of dietary exposure: A systematic study. Food and Chemical Toxicology, 91, 100-107.

https://doi.org/10.1016/j.fct.2016.03.006

\section{Published in:}

Food and Chemical Toxicology

\section{Document Version:}

Peer reviewed version

Queen's University Belfast - Research Portal:

Link to publication record in Queen's University Belfast Research Portal

\section{Publisher rights}

(c) 2016 Elsevier Ltd. This manuscript version is made available under the CC-BY-NC-ND 4.0 license http://creativecommons.org/licenses/by$\mathrm{nc}$-nd/4.0/which permits distribution and reproduction for non-commercial purposes, provided the author and source are cited.

\section{General rights}

Copyright for the publications made accessible via the Queen's University Belfast Research Portal is retained by the author(s) and / or other copyright owners and it is a condition of accessing these publications that users recognise and abide by the legal requirements associated with these rights.

Take down policy

The Research Portal is Queen's institutional repository that provides access to Queen's research output. Every effort has been made to ensure that content in the Research Portal does not infringe any person's rights, or applicable UK laws. If you discover content in the

Research Portal that you believe breaches copyright or violates any law, please contact openaccess@qub.ac.uk. 


\section{Acid-labile protein-adducted heterocyclic aromatic amines in human blood are not viable biomarkers of dietary exposure: a systematic study}

Kevin M. Cooper ${ }^{a},{ }^{\dagger},{ }^{\star}$, Sarah F. Brennan ${ }^{b, \dagger}$, Jayne V. Woodside ${ }^{b}$, Marie Cantwell ${ }^{b}$, Xiaoxiao Guo ${ }^{a}$, Mark Mooneya ${ }^{\mathrm{a}}$ Christopher T. Elliott ${ }^{\mathrm{a}}$ and Geraldine J. Cuskelly ${ }^{\mathrm{a}}$

a Institute for Global Food Security, School of Biological Sciences, Queen's University Belfast, 18-30 Malone Road, Belfast, BT9 5BN, United Kingdom

${ }^{\mathrm{b}}$ Centre for Public Health, School of Medicine, Dentistry and Biomedical Science, Queen's University Belfast, Belfast, BT12 6BA, United Kingdom

${ }^{+}$These authors contributed equally to this work.

* Corresponding author: Kevin M. Cooper, Institute for Global Food Security, School of Biological Sciences, Queen's University Belfast, 18-30 Malone Road, Belfast, BT9 5BN, United Kingdom. Tel: +44 (0) 2890 976562; Fax: +44 (0) 2890 976513; Email: k.cooper@qub.ac.uk

\section{AUTHOR ACCEPTED VERSION}

http://dx.doi.org/10.1016/i.fct.2016.03.006

\section{Food and Chemical Toxicology}

Volume 91, May 2016, Pages 100-107 


\section{Abstract}

Heterocyclic aromatic amines (HCA) are carcinogenic mutagens formed during cooking of protein-rich foods. HCA residues adducted to blood proteins have been postulated as biomarkers of HCA exposure. However, the viability of quantifying HCAs following hydrolytic release from adducts in vivo and correlation with dietary intake are unproven. To definitively assess the potential of labile HCAprotein adducts as biomarkers, a highly sensitive UPLC-MS/MS method was validated for four major HCAs: 2-amino-1-methyl-6-phenylimidazo[4,5-b]pyridine (PhIP), 2-amino-3,8-dimethylimidazo[4,5f]quinoxaline (MelQx), 2-amino-3,4,8-trimethylimidazo[4,5-f]quinoxaline (4,8-DiMelQx) and 2-amino3,7,8-trimethylimidazo[4,5-f]quinoxaline (7,8-DiMelQx). Limits of detection were 1-5 pg/ml plasma and recoveries $91-115 \%$. Efficacy of hydrolysis was demonstrated by HCA-protein adducts synthesised in vitro. Plasma and 7-day food diaries were collected from 122 fasting adults consuming their habitual diets. Estimated HCA intakes ranged from 0-2.5 mg/day. An extensive range of hydrolysis conditions was examined for release of adducted HCAs in plasma. HCA was detected in only one sample (PhIP, $9.7 \mathrm{pg} / \mathrm{ml}$ ), demonstrating conclusively for the first time that acid-labile HCA adducts do not reflect dietary HCA intake and are present at such low concentrations that they are not feasible biomarkers of exposure. Identification of biomarkers remains important. The search should concentrate on stabilised HCA-peptide markers and use of untargeted proteomic and metabolomic approaches.

Keywords: Heterocyclic amines; Serum albumin; Plasma; PhIP; LC-MS/MS; Protein adducts 


\section{Introduction}

Heterocyclic aromatic amines (HCA) are formed during combustion of tobacco and cooking of proteinrich foods, particularly meat and fish, which provide creatin(in)e and other precursors such as amino acids, sugars or other aldehydes (Cheng et al., 2006; Puangsombat et al., 2012; Aaslyng et al., 2013). 2-Amino-1-methyl-6-phenylimidazo(4,5-b)pyridine (PhIP), 2-amino-3,8-dimethylimidazo[4,5f]quinoxaline (MelQx) and 2-amino-3,4,8-trimethylimidazo[4,5-f]quinoxaline (4,8-DiMelQx) are three of the most abundant HCAs in cooked meat and fish (Lynch et al., 1995; Zhang et al., 2013) although many others have been identified (Ni et al., 2008). Their formation in the parts-per-billion concentration range on the surface of food is highly dependent upon the type of food and the method and degree of cooking, making estimation of HCA dietary exposure difficult (Alexander et al., 2002). HCAs have been extensively studied; particularly their production, metabolism (Turesky et al., 2002), formation of adducts with DNA (Schut and Snyderwine, 1999) and protein (Peng et al., 2012), their quantification (Murkovic, 2011) and implications for human health. There is strong evidence from animal models (Adamson et al., 1990; Shirai et al., 1997; Paulsen et al., 1999) and in vitro studies (Gooderham et al., 2007) of the carcinogenic and mutagenic properties of HCAs. Although several case-control studies in humans have reported positive associations between consumption of welldone red meat (assumed to contain elevated HCA concentrations) and incidence of colon, breast, lung and gastric cancers (Sinha, 2002), evidence correlating HCA dietary intake and cancers can be equivocal (Sugimara et al., 2004; Tang et al., 2013).

To overcome limitations of estimating HCA intake by food frequency questionnaires, direct measurement of in vivo biomarkers of HCA exposure is desirable. Whilst urine HCA metabolic profiles have been described (Holland et al., 2004), urinary biomarkers are transient, representing only daily HCA exposure and allowing intermittent intake to go undetected (Turesky and Le Marchand, 2011). Long-term biomarkers of HCA exposure are still needed for use as internal dosimeters in epidemiological studies. As with many environmental and dietary toxicants (Rappaport et al., 2012), blood protein adducts have been postulated as potential biomarkers. HCAs are subject to in vivo metabolic activation via $\mathrm{N}$-hydroxylation of their exocyclic amine groups. The resulting reactive intermediates bind to cysteine residues of proteins via sulfinamide linkages (Peng and Turesky, 2014; Chepanoske et al., 2004). The arylsulfinamide bonds formed between HCAs and cysteine in 
haemoglobin $\left(\mathrm{Hb}-\mathrm{Cys}^{93}\right)$ and serum albumin $\left(\mathrm{HSA}^{-\mathrm{Cys}}{ }^{34}\right)$ are known to be labile, undergoing hydrolysis under conditions commonly used to digest proteins. This labile characteristic has been used to monitor exposure to other carcinogenic aromatic amines following hydrolytic release of the intact compound from haemoglobin adducts (Gan et al., 2004).

Several studies have demonstrated the liberation of HCAs from protein or DNA adducts and their subsequent quantification as the intact HCA. However, these are almost exclusively studies of in vitro HCA-adducts created using liver microsome systems (Lynch et al., 1991) or conjugation using reactive intermediates (Peng and Turesky, 2011; Wang et al., 2015). Furthermore, some studies are applied to cell cultures (Crosbie et al., 2000) or extraction procedures from plasma (Lezamiz et al., 2008) or proteins (Busquets et al., 2006) fortified with free HCAs but not to incurred samples containing known HCA-protein adducts. The concentration of adducts in such in vitro studies may be significantly greater than would be expected in vivo, and the efficacy of hydrolysis procedures to release protein-adducted HCAs is unknown in those studies which employ only fortification with free HCAs. Only one study (Magagnotti et al., 2000) has claimed to quantify an HCA adducted to blood proteins following its release by hydrolysis from the blood of human subjects consuming normal diets. Magagnotti observed $1.5 \mathrm{pg} \mathrm{PhIP/mg} \mathrm{HSA} \mathrm{(equivalent} \mathrm{to} \mathrm{approximately} 70 \mathrm{pg} \mathrm{PhIP} / \mathrm{ml}$ plasma) in meat-eating participants after mild acid hydrolysis and liquid-liquid extraction followed by immunoaffinity chromatography clean-up. PhIP concentrations ten-fold lower were detected in vegetarian participants. PhIP derived from haemoglobin adducts was half that observed from HSA adducts. The fact that this study has not been reproduced in the following years suggests that release and quantification of protein-adducted HCAs is problematic. The lack of literature concerning labile HCA adducts and the focus of recent studies on HCA-DNA adducts and characterisation of stable HCA-peptide adducts support this idea. However, the candidacy of labile HCA-protein adducts as biomarkers of HCA exposure has not been conclusively ruled out or, it would appear, subjected to systematic study. PhIP-albumin adducts, in particular, continue to be proposed as potential biomarkers (Turesky and Le Marchand, 2011). The current study aims to conclusively assess the suitability of labile HCA adducts in plasma as biomarkers of dietary HCA exposure by employing high sensitivity mass spectrometry, in vitro HCA-protein control adducts to evaluate efficacy of hydrolysis, and a cohort of human blood samples accompanied by detailed HCA dietary intake information collected in a cross-sectional study of participants consuming their habitual diets. 


\section{Materials and methods}

\subsection{Materials}

Reference standards 2-amino-1-methyl-6-phenylimidazo[4,5-b]pyridine (PhIP), 2-amino-3,8-dimethylimidazo [4,5-f]quinoxaline (MelQx), 2-amino-3,4,8-trimethylimidazo [4,5-f]quinoxaline (4,8-DiMelQx), 2-amino-3,7,8-trimethylimidazo [4,5-f]quinoxaline (7,8-DiMelQx) and deuterium labelled internal standards (I.S.) D3-PhIP, D3-MelQx and D3-4,8-DiMelQx (each isotopically labelled at the methyl group at the $\mathrm{N}-1$ position of the imidazo ring) were purchased from Toronto Research Chemicals (North York, ON, Canada). Mixed standard solutions prepared in LCMS grade methanol were stored at $4 \circ \mathrm{C}$. Human liver microsomes (50 donor pool) were obtained from Invitrogen Ltd (Paisley, UK), recombinant human sulfotransferase 1A1 from US Biological (Swampscott, MA, USA), and NADPH regenerating system from BD Biosciences (Oxford, UK). Unless stated, all other chemicals, including human haemoglobin (H7379) and human serum albumin (A3782) were obtained from Sigma-Aldrich (Dorset, UK). Slide-A-Lyzer dialysis cassettes and Pierce BCA Protein Assay Kit were obtained from Thermo Fisher Scientific (Rockford, IL, USA). Oasis MCX strong cation exchange solid phase extraction cartridges ( $1 \mathrm{ml}, 30 \mathrm{mg}$ ) were obtained from Waters Corporation (Milford, MA, USA).

\subsection{Cross-sectional study}

\subsubsection{Participants and food diaries}

Healthy cross-sectional study participants, recruited via poster and email advertisement and through word-of-mouth, were given full study information and screened for eligibility. Those under 18 years were excluded, as were smokers, due to potential exposure to polycyclic aromatic hydrocarbons. Eligible participants provided written, informed consent. They received 7-day food diaries and detailed instructions on recording their dietary intake, with particular emphasis on describing cooking methods and 'doneness' level of any meat consumed. Participants recorded their dietary intake for seven consecutive days and returned within two days of completing their diary. The study was conducted according to the guidelines laid down in the declaration of Helsinki and all procedures involving human subjects were approved by the School of Medicine, Dentistry and Biomedical Sciences Research Ethics Committee of Queen's University Belfast. 


\subsubsection{Blood collection}

Participants fasted (water only allowed) for at least $12 \mathrm{~h}$ prior to attending the cross-sectional study visit to ensure removal of free circulating HCAs from plasma. Participants provided a $50 \mathrm{ml}$ blood sample, collected in anticoagulant plasma tubes and serum tubes, by staff trained in venepuncture. Serum tubes were allowed to coagulate at room temperature for $1 \mathrm{~h}$ while plasma tubes were refrigerated. Serum and plasma were obtained by centrifugation, buffy coat being discarded from plasma tubes. Serum and plasma were aliquotted and stored at $-80^{\circ} \mathrm{C}$ for long-term storage and at $20^{\circ} \mathrm{C}$ during the analysis phase.

\subsubsection{Food diary review}

Completed food diaries were reviewed by a member of the research team asking participants to confirm the food portions they recorded using a photographic Portion Size Atlas (Nelson et al., 2002). Participants were also asked to clarify the cooking methods used and to describe the 'doneness' level of any meat consumed by matching it to a series of published colour-printed 'meat doneness' pictures, including beef burgers, bacon and steak (Sinha et al., 1998a; 1998b), and steak 'doneness' pictures produced by the research team and described elsewhere (Chan et al., 2013). The additional information obtained by this review of food diaries improved the accuracy of the estimated HCA dietary intake.

\subsubsection{Food diary analyses}

Dietary HCA intake was determined by analysing information from the self-reported food diaries using the dietary analysis program WISP v3.0 (Tinuviel, UK). Certain food items in WISP are available to select under various food codes which differ by cooking method. The database was updated, for the purposes of this study, with additional meat food codes based on cooking methods and varying levels of 'doneness'. Nutrient data within WISP were also updated to include values for the commonly consumed HCAs (MelQx, DiMelQx and PhIP) assigned to the newly updated food codes and cooking methods. Information on HCA content was obtained from the CHARRED online database (US National Cancer Institute, 2015) and a second published database (Alaejos and Afonso, 2011). HCA values were applied directly to 'meat only' food codes and, for composite dishes, were calculated from 
disaggregated meat content using published data (Fitt et al., 2009) or estimated from average percentage meat content in commercial dishes available from UK supermarkets. Meat 'doneness' level for composite dishes was assumed to be 'well done' for the present analyses. Consequently, mean total HCA intake (ng/day) and intake of the individual HCAs (MelQx, DiMelQx and PhIP) were estimated from detailed self-reported information on type, amount, cooking method and 'doneness' of meat consumed.

\subsection{Preparation and characterisation of in vitro HCA-protein adducts}

To act as positive controls in the analysis of HCA-protein adducts, PhIP and MelQx were conjugated in vitro to human serum albumin and haemoglobin using human hepatic microsomes essentially as described by Lynch et al. (1993). Human microsomes were selected over the more commonly used rodent microsomes because significant species differences in catalytic activity and regioselectivity of HCA metabolism have been shown and adducts which closely mimic the structures formed by human metabolism in vivo were required for this study (Turesky et al., 2002; Cheung et al., 2005). Proteins (10 mg) were mixed with HCA $(25 \mu \mathrm{g})$, human liver microsomes $(50 \mu \mathrm{l})$ and a NADPH regenerating system $(100 \mu \mathrm{l}$ NADP+ solution A and $20 \mu \mathrm{l}$ enzyme solution B) in a total volume of $1 \mathrm{ml}$ Tris- $\mathrm{HCl}$ buffer $(50 \mathrm{mM}, \mathrm{pH} 7.6)$. Reagents were mixed in a $37^{\circ} \mathrm{C}$ shaking water bath for $18 \mathrm{~h}$ then centrifuged at $100000 \mathrm{~g}$ for $1 \mathrm{~h}$ at $4^{\circ} \mathrm{C}$. Supernatants were diluted with $3 \mathrm{ml}$ deionised water before exhaustive dialysis against saline ( $4 \mathrm{~L}$ changed seven times over $72 \mathrm{~h}$ ) to remove unbound HCAs. The inclusion in the microsomal reaction mixture of a Phase II enzyme, sulphotransferase-1A1 (with adenosine 3phosphate 5-phosphosulfate), was investigated but no increase in adduction of PhIP to HSA was evident. Negative control reactions, omitting the liver microsomes, were also conducted to demonstrate that HCA adduction was via covalent binding following enzymatic metabolism rather than non-specific adsorption to the proteins. Total protein concentrations were determined by bicinchoninic acid colourimetric test using protein-specific standard curves. Concentrations of acid-labile HCAs adducted to proteins were determined by LC-MS/MS as described below following acid hydrolysis $\left(0.8 \mathrm{M} \mathrm{HCl}\right.$ at $80^{\circ} \mathrm{C}$ for $\left.2 \mathrm{~h}\right)$ and liquid-liquid extraction with ethyl acetate. 


\subsection{Extraction and quantification of HCAs from blood}

A highly sensitive method was developed and validated for the hydrolysis, extraction and quantification by liquid chromatography tandem mass spectrometry of HCAs in human blood.

\subsubsection{Adduct hydrolysis methods}

A pooled plasma sample was prepared from 13 cross-sectional study participants in the highest tertile of HCA intake based on food diaries described below. The estimated mean daily HCA intake associated with this pooled sample was $1.2 \mu \mathrm{g} \mathrm{HCA} /$ day. Nine acid and alkaline hydrolysis conditions were assessed for release of protein-adducted HCAs from this pooled plasma prior to extraction and quantification as described below. Conditions were based on literature reports of HCA hydrolysis from cooked foods, hair and in vitro blood protein and DNA adducts (Table 1).

\subsubsection{HCA extraction method}

An unusually large plasma sample size $(1 \mathrm{ml})$ was used to maximise method sensitivity. Plasma samples, in 50ml polypropylene centrifuge tubes, were fortified with internal standards (D3-PhIP, D3MelQx and D3-4,8-DiMelQx) at $2 \mathrm{pg} / \mathrm{ml}$ and hydrolysed with $10 \mathrm{ml}$ of acid or alkali in a shaking water bath for between 1 and $18 \mathrm{~h}$ as listed in Table 1 . Acid hydrolysed samples were adjusted to $\mathrm{pH} 11.5 \pm$ 0.5 with $10 \mathrm{M} \mathrm{NaOH}$. Double liquid-liquid extraction was performed using $9 \mathrm{ml}$ and $8 \mathrm{ml}$ LCMS grade ethyl acetate (mixing for $60 \mathrm{sec}$, centrifuge $1500 \mathrm{~g}$ for $10 \mathrm{~min}$ ). Combined supernatant was reduced to approximately $5 \mathrm{ml}$ under nitrogen in a $45^{\circ} \mathrm{C}$ water bath then acidified with $10 \mu \mathrm{l}$ glacial acetic acid. Extracts were applied to MCX cation exchange solid phase extraction cartridges previously conditioned with $1 \mathrm{ml}$ each of 5\% aqueous ammonia in methanol, $2 \%$ acetic acid in methanol, and $100 \%$ methanol. Loaded columns were washed with $1 \mathrm{ml}$ each of $40 \mathrm{mM} \mathrm{HCl}$ in methanol, $100 \%$ methanol, and $2 \%$ aqueous ammonia in $15 \%$ methanol, then eluted with $1 \mathrm{ml}$ of $5 \%$ aqueous ammonia in methanol (Holland et al., 2004). Eluates were evaporated to dryness at $55^{\circ} \mathrm{C}$ under nitrogen, reconstituted in $100 \mu \mathrm{l}$ of $30 \mathrm{mM}$ ammonium formate pH 9.5 in $20 \%$ acetonitrile and transferred to $2 \mathrm{ml} \mathrm{HPLC}$ microvials containing $200 \mu \mathrm{l}$ glass inserts.

\subsubsection{HCA quantification by LC-MS/MS}


HCAs were separated on a BEH C18 $1.7 \mu \mathrm{m}$ column $(50 \times 2.1 \mathrm{~mm})$ and Acquity UPLC $\otimes$ binary pump system and detected by Xevo TQS tandem mass spectrometer (Waters Corporation, Manchester, UK). Instrument settings and LC gradient were as published previously (Cooper et al., 2014). Injection volume was increased to $7 \mathrm{ml}$ to maximise method sensitivity. HCA fragmentation transitions are listed in Table 2. Deuterium labelled internal standards were included in all samples prior to extraction and in solvent calibration standards to improve quantification by compensating for extraction efficiency and matrix ion suppression effects. However, D3-PhIP was omitted from quantification of PhIP due to an interfering peak eluting at the same retention time in acid hydrolysed plasma samples. HCA identification was based on peak retention time and the presence of both a primary (quantitative) ion transition peak and a secondary (confirmatory) peak, the ratio of which had to agree to within fixed tolerances of the corresponding ratio in standards (Cooper et al., 2014). Confidence in identification of an analyte is crucial when quantifying a low concentration biomarker, so strict ion ratio tolerances were applied ( $\pm 30 \%$ for PhIP, 25\% for MelQx, 20\% for 4,8-and 7,8-DiMelQx) based on guidance in European Commission Decision 2002/657 for the analytical performance of methods in the veterinary pharmaceuticals field. While this document is not directly applicable to natural carcinogens such as HCAs, it is the opinion of the authors that similar identification criteria should be applied to analysis of suspected carcinogens whenever possible to avoid misidentification, particularly in methods involving acid hydrolysis which increases chromatogram background noise.

\subsubsection{LC-MS/MS method validation}

The analytical method employing the representative hydrolysis protocol described below was validated using a pool of nominally blank plasma obtained from participants with the lowest HCA intake based on their 7-day food diaries. Seven aliquots of pooled plasma were fortified with HCAs at $10 \mathrm{pg} / \mathrm{ml}$, extracted and quantified as described above. This was repeated on three days to enable calculation of intra- and inter-assay variations (\% RSD). Limits of detection (LOD) and quantification (LOQ) were calculated based on signal-to-noise $(\mathrm{s} / \mathrm{n})$ ratios of the least intense transition peak for each HCA, using unsmoothed peaks (LOD $s / n>3$, LOQ $s / n>10$ ). In vitro HCA-protein adducts were used as positive controls to prove the efficacy of the hydrolysis and extraction procedures. Blank plasma was fortified with in vitro adducts at $3-20 \mathrm{pg} / \mathrm{ml}$ based on the measured acid-labile HCAs incorporated in the adducts (Table 3). 


\section{Results}

\subsection{Characterisation of in vitro HCA-protein adducts}

Incorporation of acid-labile HCAs into human blood proteins following in vitro incubation with human hepatic microsomes is shown in Table 3. HCAs released by acid hydrolysis $\left(0.8 \mathrm{M} \mathrm{HCl}\right.$ at $80^{\circ} \mathrm{C}$ for $\left.2 \mathrm{~h}\right)$ and liquid-liquid extraction with ethyl acetate ranged from 6.5 to $23.5 \mathrm{ng} \mathrm{HCA} / \mathrm{mg}$ protein.

\subsection{LC-MS/MS method validation}

LC-MS/MS chromatograms illustrating the quantitative and confirmatory transition peaks for each of the four HCAs fortified into plasma at $5 \mathrm{pg} / \mathrm{ml}$ prior to acid hydrolysis and extraction are shown in Figure 1. Analytical method validation data are listed in Table 4. Assay performance was acceptable with all RSDs below $10 \%$, recovery of fortified HCAs ranging from $91-116 \%$ and limits of detection ranging from 1-5 pg/ml plasma. PhIP LOD was higher than other HCAs due to the low intensity of its confirmatory peak (Figure 1). Solvent calibration curve linearity was typically $r^{2}>0.98$ over the range equivalent to $1-30 \mathrm{pg} / \mathrm{ml}$ plasma. The efficacy of the validated hydrolysis and extraction protocol was demonstrated by fortifying blank plasma with HCA-protein adducts synthesised in vitro. Recovery of HCAs adducted to HSA and $\mathrm{Hb}$ was on average $65 \%$ for PhIP and $114 \%$ for MelQx based on acidlabile HCAs incorporated in the adducts (Table 3).

\subsection{Hydrolysis method selection}

None of the four HCAs was observed and confirmed in the plasma pool of high intake participants following any of the nine hydrolysis conditions described (Table 1). In order to analyse a wider range of individual plasmas from the highest HCA participants, a representative hydrolysis protocol was selected. It was observed that use of $6 \mathrm{M} \mathrm{HCl}$ or incubation at $95^{\circ} \mathrm{C}$ resulted in higher background noise in chromatograms, potentially masking small $\mathrm{HCA}$ peaks. Hydrolysis using $2 \mathrm{M} \mathrm{HCl}$ for $1 \mathrm{~h}$ at $80^{\circ} \mathrm{C}$ was chosen as the representative method (Busquets et al., 2006), supported by an earlier observation of a low concentration PhIP peak (confirmatory peak not visible) in a single plasma sample under similar conditions. 


\subsection{Cross-sectional study}

Blood samples and completed 7-day food diaries were obtained from 122 participants. Participants were categorised into tertiles based on estimated total HCA dietary intake (Table 5) which ranged from zero to $2.5 \mu \mathrm{g} / \mathrm{d}$.

\subsection{Survey of acid-labile HCAs in plasma of high HCA intake participants}

Plasma from 35 participants with the highest HCA intakes (estimated 0.7-2.5 $\mu \mathrm{g} \mathrm{HCA} /$ day) were tested for acid-labile HCA concentration using the representative hydrolysis protocol. Only one sample was confirmed to contain an acid-labile HCA above the analytical limits of detection: PhIP at $9.7 \mathrm{pg} / \mathrm{ml}$ plasma from a participant with estimated HCA intake of $0.9 \mu \mathrm{g} / \mathrm{day}$. Serum from the same participant contained acid-labile PhIP at $8.1 \mathrm{pg} / \mathrm{ml}$. The paucity of acid-labile HCAs led us to revisit the sample preparation method of Magagnotti et al. (2000) who isolated serum albumin by precipitation before hydrolysis with $0.1 \mathrm{M} \mathrm{HCl}$ for $1 \mathrm{~h}$ at $80^{\circ} \mathrm{C}$ followed by liquid-liquid extraction with ethyl acetate and clean up by immunoaffinity chromatography (as opposed to solid phase extraction used in the current study). We purified $75 \mathrm{mg}$ albumin from a pool of serum from high HCA intake participants (mean intake $1.8 \mu \mathrm{g} / \mathrm{d}$ ) using ammonium sulphate/acetic acid precipitation before hydrolysis under Magagnotti's conditions and extraction by our described method. No acid-labile HCAs were detected in this purified albumin sample.

\section{Discussion}

Residues of HCAs adducted to blood proteins have been postulated for some years as potential medium-term biomarkers of carcinogenic HCA exposure (Peng and Turesky, 2011; Magagnotti et al., 2000; Dingley et al., 1999). However, the viability of quantifying HCAs following their release from such adducts in vivo has not been proven in people consuming diets encompassing the normal range of HCA intakes. To act as meaningful biomarkers, HCAs released from blood proteins must correlate with the known HCA exposure of the individual - primarily their dietary intake in non-smokers. To this end, blood samples were collected from 122 participants along with detailed food intake diaries, which demonstrated estimated HCA dietary intakes ranging from zero to $2.5 \mu \mathrm{g} / \mathrm{d}$. A highly sensitive liquid chromatography tandem mass spectrometry method was developed and validated for the major 
HCAs in plasma. An extensive range of hydrolysis conditions was examined for the release of adducted HCAs in plasma from participants with the highest HCA intakes. A HCA (PhIP at 9.7 pg/ml) was detected in only one plasma sample (participant HCA intake $0.9 \mu \mathrm{g} / \mathrm{d}$ ), demonstrating conclusively, to our knowledge for the first time, that acid-labile HCA-blood protein adducts do not reflect dietary HCA intake and are present at such low concentrations that they are not suitable biomarkers of dietary exposure to HCAs.

In vitro control adducts of HCAs in blood proteins were prepared by incubation with human hepatic microsomes. Acid-labile MelQx in albumin was higher by an estimated factor of five than observed by Lynch et al. (1993) in a similar system, presumably due to our longer reaction time and greater excess of starting MelQx, since Lynch demonstrated in vitro adduction was time and concentration dependent. Lynch et al. (1993) also demonstrated that in vitro MeIQx adducts were approximately twice as likely to be hydrolysed to intact MelQx from haemoglobin than from albumin adducts. This was not evident for MeIQx in the current study, but was seen with PhIP adducts. It is generally thought that total HCA adduction to albumin in vivo is substantially greater than to haemoglobin (Turesky and Le Marchand, 2011); however, one study (Magagnotti et al., 2000) demonstrated acid labile PhIP-Hb adducts to be only two-fold lower than albumin adducts. Our protein adducts prepared in vitro contain HCAs at concentrations approximately four orders of magnitude greater than PhIPprotein adducts described in vivo in the few studies which have quantified albumin or haemoglobin adducts in people consuming conventional diets (Magagnotti et al., 2000) or dietary-relevant doses of radiolabelled PhIP (Dingley et al., 1999). This high level of adduction is similar to that reported for in vitro adduction of reactive metabolites of PhIP to albumin (Peng and Turesky, 2011).

The analytical method applied in this study (adduct hydrolysis, HCA extraction by liquid-liquid extraction, clean-up by solid phase extraction and quantification by UPLC-MS/MS) was demonstrated to be fit-for-purpose by several means. Firstly, validation of the method using plasma repeatedly fortified with HCAs and isotopically labelled internal standards at low concentrations demonstrated satisfactory assay performance (analyte recovery, reproducibility and repeatability) and excellent sensitivity, limits of detection ranging from 1 to 5 pg HCA per ml plasma. Secondly, HCA-protein adducts were synthesised in vitro and used to demonstrate the method was capable of releasing intact HCAs by hydrolysis and extracting them quantitatively from plasma at low parts-per-trillion 
concentrations. Thirdly, the widest range of HCA hydrolysis conditions yet published was examined, encompassing, but not limited to, published conditions from diverse in vitro and in vivo HCA-adduct studies. While the HCA-protein literature concentrates on acidic hydrolysis conditions, we also included selected alkaline conditions (previously applied to hydrolysis of DNA and melanin adducts of HCAs) to give the broadest opportunity for liberation of protein-bound HCAs. Fourthly, the finding of PhIP in a single plasma sample demonstrated the method was capable of detecting acid-labile PhIP in participants with normal dietary intakes.

Confidence in the identification of analytes is crucial when measuring low concentrations of compounds in complex biological matrices, particularly compounds such as HCAs which share common structures and fragmentation patterns, and samples undergoing hydrolysis which increases chromatogram background noise. The presence of a second fragmentation peak to confirm an analyte's identity should be a prerequisite in such analyses, although this is not always the case in the published literature of HCAs. The current study insisted on the presence of secondary peaks and included these in the calculation of limits of detection. Furthermore, the ratio of confirmatory to primary quantitation peaks (ion ratio) was monitored in every sample to ensure agreement with the same ratio in calibration standards.

Magagnotti et al. (2000) is currently the only study to have quantified a HCA (PhIP) following hydrolysis of blood proteins from humans consuming conventional diets. They observed $1.5 \mathrm{pg}$ $\mathrm{PhIP} / \mathrm{mg}$ HSA (equivalent to approximately $70 \mathrm{pg} \mathrm{PhIP} / \mathrm{ml}$ plasma) in meat-eating participants after mild acid hydrolysis of $100 \mathrm{mg}$ purified albumin, and PhIP concentrations ten-fold lower in vegetarian participants. The methodology described in the current study is easily capable of measuring such quantities, with HCA limits of detection from 1 to $5 \mathrm{pg} / \mathrm{ml}$ plasma. It should be highlighted that Magagnotti et al. (2000) did not monitor a secondary peak for PhIP, which could cast doubt on the identification of this analyte. The secondary fragment of PhIP $(\mathrm{m} / \mathrm{z} 225.2>183.2)$ yields a peak approximately ten-fold less intense than the primary peak used to quantify the compound. Magagnotti reported a PhIP limit of detection similar to that of our current study but without the presence of this confirmatory peak. Thus, our method is capable of confirming the presence of HCAs in plasma to a significantly greater degree of certainty. To our knowledge the work of Magagnotti has not been reproduced in the scientific literature. The relative silence in the literature concerning validated HCAprotein biomarkers, which have been discussed for over two decades, suggests that other 
researchers have been unable to build on the promise of this study. The identification and validation of a labile HCA-protein biomarker is undoubtedly hampered by evidence that less than $10 \%$ of material derived from HCAs and bound to protein in vivo can be hydrolysed to the intact HCA (Lynch et al., 1993; Turesky et al., 1987).

A review of potential HCA biomarkers by Prof Robert Turesky et al. (2011) stated that "the inefficient binding of HCAs to haemoglobin will probably preclude the development of $\mathrm{HCA}-\mathrm{Hb}$ adducts as biomarkers in humans", and "... it is unlikely that the sulfinamide adduct of MelQx with human serum albumin can be used as a dosimeter for human...exposure." Prof Turesky continued, saying "further investigations on the implementation of PhIP blood protein adducts in human population studies are warranted." In the opinion of the authors, the current study provides conclusive proof for the first time, using state-of-the-art mass spectrometry, that blood plasma protein adducts of both PhIP and MelQx, even if they are present in significant concentrations in people consuming normal diets, are insufficiently acid-labile to yield intact HCAs which may act as biomarkers of HCA exposure.

Recent HCA biomarker studies have focused on detection and characterization of HCA-DNA adducts (Tang et al., 2013; Gu et al., 2012; Brown et al., 2001) which reflect the actual detrimental impact of these carcinogens at the genomic level rather than the indicative harm represented by protein adducts. Other studies are aiming to detect HCA-peptide adducts following proteolysis by stabilising the adduct's arylsulfinamide bond via oxidation to an arylsulfonamide bond which is resistant to acid, heat and reducing agents commonly used in proteolytic digestion (Peng et al., 2012; Peng and Turesky 2013; 2014). While characterization of such stabilised adducts is ongoing (Peng and Turesky, 2014), their existence has yet to be demonstrated in human blood in vivo. However, an alternative approach is also warranted. Markers of HCA status, or more general dietary factors such as red meat intake, may be revealed via untargeted proteomic, lipidomic or metabolomic analyses. Preliminary metabolomic studies of the cohort of blood samples collected in this study are currently underway at the Institute for Global Food Security at Queen's University Belfast.

\section{Conclusions}


Carcinogenic and mutagenic heterocyclic aromatic amines are known to form adducts with blood proteins. The characterisation and use of such adducts as internal dosimeters in epidemiological studies of HCA exposure have been studied for many years without a clear candidate adduct being proven in vivo. The hydrolytic release from protein adducts of intact HCAs which distinguished between vegetarians and meat-eaters was demonstrated fifteen years ago (Magagnotti et al., 2000) but correlation with dietary HCA intake by this method has not been repeated since. The current study systematically assessed a range of hydrolysis conditions for release of HCAs from in vivo plasma adducts measured by validated mass spectrometry (limits of detection 1-5 pg/ml plasma). Food diaries from cross-sectional study participants demonstrated HCA intakes ranging from 0-2.5 $\mu \mathrm{g} / \mathrm{day}$. Despite sufficient assay sensitivity and use of positive control HCA-protein adducts synthesised in vitro, a HCA was detected in only one sample (PhIP, $9.7 \mathrm{pg} / \mathrm{ml})$ demonstrating that acid-labile HCA adducts do not reflect dietary HCA intake as previously postulated and are present at such low concentrations that they are not viable biomarkers of HCA exposure. This conclusion is in keeping with the current direction of research in this area which aims to fully characterize the structure of HCAprotein adducts and to utilize stabilised HCA-peptide adducts as dosimeters following protein digestion.

\section{Acknowledgements}

Grateful thanks are expressed to all participants in the FoodCAP project for blood donations and participation in the cross-sectional and intervention studies, and to Dr Sheung-Hang Chan for assistance with recruitment.

\section{Declaration of interest}

This work was supported financially by the World Cancer Research Fund UK (grant number 2010/255). The authors report no conflicts of interest. 


\section{References}

Aaslyng MD, Duedahl-Olesen L, Jensen K, Meinert L. (2013). Content of heterocyclic amines and polycyclic aromatic hydrocarbons in pork, beef and chicken barbecued at home by Danish consumers. Meat Sci 93:85-91.

Adamson RH, Thorgeirsson UP, Snyderwine EG, Thorgeirsson SS, Reeves J, Dalgard DW, et al. (1990). Carcinogenicity of 2-amino-3-methylimidazo[4,5-f]quinoline in nonhuman primates: Induction of tumors in three macaques. Jpn J Cancer Res 81:10-14.

Alaejos MS, Afonso AM. (2011). Factors that affect the content of heterocyclic aromatic amines in foods. Compr Rev Food Sci F 10:52-108.

Alexander J, Reistad R, Hegstad S, Frandsen H, Ingebrigtsen K, Paulsen JE, et al. (2002). Biomarkers of exposure to heterocyclic amines: approaches to improve the exposure assessment. Food Chem Toxicol 40:1131-1137.

Bessette EE, Guenther EA, Dingley KH, Cosman M, Harvey CA, Shields SJ, et al. (2009). Biomonitoring of carcinogenic heterocyclic aromatic amines in hair: a validation study. Chem Res Toxicol 22:14541463.

Brown K, Guenther EA, Dingley KH, Cosman M, Harvey CA, Shields SJ, et al. (2001). Synthesis and spectroscopic characterization of site-specific 2-amino-1-methyl-6-phenylimidazo[4,5-b]pyridine oligodeoxyribonucleotide adducts. Nucleic Acids Res 29:1951-1959.

Busquets R, Puignou L, Galceran MT. (2006). Determination of 2-amino-1-methyl-6-phenylimidazo [4,5-b]pyridine (PhIP) in hemoglobin using on-line coupling of restricted access material to liquid chromatography-mass spectrometry. Anal Chim Acta 559:45-53.

Chan S-H, Moss BW, Farmer LJ, Gordon A, Cuskelly GJ. (2013). Comparison of consumer perception and acceptability for steaks cooked to different endpoints: Validation of photographic approach. Food Chem 136:1597-1602.

Cheng K, Chen F, Wang M. (2006). Heterocyclic amines: Chemistry and health. Mol Nutr Food Res 50:1150-1170.

Chepanoske C, Brown K, Turteltaub KW, Dingley KH. (2004). Characterization of a peptide adduct formed by $\mathrm{N}$-acetoxy-2-amino-1-methyl-6-phenylimidazo[4,5-b]pyridine (PhIP), a reactive intermediate of the food carcinogen PhIP. Food Chem Toxicol 42:1367-1372.

Cheung C, Ma XC, Krausz KW, Kimura S, Feigenbaum L, Dalton TP, et al. (2005). Differential metabolism of 2-amino-1-methyl-6-phenylimidazo[4,5-b]pyridine (PhIP) in mice humanized for CYP1A1 and CYP1A2. Chem Res Toxicol 18:1471-1478.

Cooper KM, Jankhaikhot N, Cuskelly G. (2014). Optimised extraction of heterocyclic aromatic amines from blood using hollow fibre membrane liquid-phase microextraction and triple quadrupole mass spectrometry. J Chromatogr A 1358:20-28. 
Crosbie S, Murray S, Boobis AR, Gooderham NJ. (2000). Mass spectrometric detection and measurement of N-2-(2 '-deoxyguanosin-8-yl)PhIP adducts in DNA. J Chromatogr B 744:55-64.

Dingley KH, Curtis KD, Nowell S, Felton JS, Lang NP, Turteltaub KW. (1999). DNA and protein adduct formation in the colon and blood of humans after exposure to a dietary-relevant dose of 2-amino-1methyl-6-phenylimidazo[4,5-b]pyridine. Cancer Epidem Biomar 8:507-512.

European Commission Decision 2002/657/EC of 12 August 2002 implementing Council Directive $96 / 23 / E C$ concerning the performance of analytical methods and the interpretation of results. Off J Eur Comm L221:8-36.

Fitt E, Prynne CJ, Teucher B, Swan G, Stephen AM. (2009). National diet and nutrition survey: assigning mixed dishes to food groups in the nutrient databank. J Food Compos Anal 22:S52-S56.

Gan J, Skipper PL, Gago-Dominguez M, Arakawa K, Ross RK, Yu MC, et al. (2004). Alkylanilinehemoglobin adducts and risk of non-smoking-related bladder cancer. J Natl Cancer Inst 96:14251431.

Gooderham NJ, Creton S, Lauber SN, Zhu H. (2007). Mechanisms of action of the carcinogenic heterocyclic amine PhIP. Toxicol Lett 168:269-277.

Gu D, Turesky RJ, Tao Y, Langouet SA, Nauwelaers GC, Yuan J-M, et al. (2012). DNA adducts of 2amino-1-methyl-6-phenylimidazo[4,5-b]pyridine and 4-aminobiphenyl are infrequently detected in human mammary tissue by liquid chromatography/tandem mass spectrometry. Carcinogenesis 33:124-130.

Holland R, Taylor J, Schoenbachler L, Jones RC, Freeman JP, Miller TW, et al. (2004) Rapid biomonitoring of heterocyclic aromatic amines in human urine by tandem solvent solid phase extraction liquid chromatography electrospray ionization mass spectrometry. Chem Res Toxicol 17:1121-1136.

Kataoka H, Miyake M, Nishioka S, Matsumoto T, Saito K, Mitani K. (2010). Formation of protein adducts of 2-amino-1-methyl-6-phenylimidazo[4,5-b]pyridine in cooked foods. Mol Nutr Food Res 54:1039-1048.

Lezamiz J, Barri T, Jönsson JÅ, Skog K. (2008). A simplified hollow-fibre supported liquid membrane extraction method for quantification of 2-amino-1-methyl-6-phenylimidazo[4,5-b]pyridine (PhIP) in urine and plasma samples. Anal Bioanal Chem 390:689-696.

Lynch A, Murray S, Boobis AR, Davies DS, Gooderham NJ. (1991). The measurement of MelQx adducts with mouse hemoglobin in vitro and in vivo - implications for human dosimetry.

Carcinogenesis 12:1067-1072.

Lynch A, Murray S, Gooderham NJ, Boobis AR. (1995). Exposure to and activation of dietary heterocyclic amines in humans. Crit Rev Oncol 21:19-31.

Lynch A, Murray S, Zhao K, Gooderham NJ, Boobis AR, Davies DS. (1993). Molecular dosimetry of the food-borne carcinogen MelQx using adducts of serum-albumin. Carcinogenesis 14:191-194. 
Magagnotti C, Orsi F, Bagnati R, Celli N, Rotilio D, Fanelli R, et al. (2000). Effect of diet on serum albumin and hemoglobin adducts of 2-amino-1-methyl-6-phenylimidazo[4,5-b]pyridine (PhIP) in humans. Int J Cancer 88:1-6.

Murkovic M. (2007). Analysis of heterocyclic aromatic amines. Anal Bioanal Chem 389:139-146.

Nelson M, Atkinson M, Meyer J. (2002). Food portion sizes: a photographic atlas. 3rd edn. London: Food Standards Agency, MAFF Publications.

Ni W, McNaughton L, LeMaster DM, Sinha R, Turesky RJ. (2008). Quantitation of 13 heterocyclic aromatic amines in cooked beef, pork, and chicken by liquid chromatography-electrospray ionization/tandem mass spectrometry. J Agric Food Chem 56:68-78.

Paulsen JE, Steffensen I-L, Andreassen A, Vikse R, Alexander J. (1999). Neonatal exposure to the food mutagen 2-amino-1-methyl-6-phenylimidazo[4,5-b]pyridine via breast milk or directly induces intestinal tumors in multiple intestinal neoplasia mice. Carcinogenesis 20:1277-1282.

Peng L, Dasari S, Tabb DL, Turesky RJ. (2012). Mapping serum albumin adducts of the food-borne carcinogen 2-amino-1-methyl-6-phenylimidazo[4,5-b]pyridine by data-dependent tandem mass spectrometry. Chem Res Toxicol 25:2179-2193.

Peng L, Turesky RJ. (2011). Mass spectrometric characterization of 2-amino-1-methyl-6phenylimidazo[4,5-b]pyridine $\mathrm{N}$-oxidized metabolites bound at Cys(34) of human serum albumin. Chem Res Toxicol 24:2004-2017.

Peng L, Turesky RJ. (2013). Capturing labile sulfenamide and sulfinamide serum albumin adducts of carcinogenic arylamines by chemical oxidation. Anal Chem 85:1065-1072.

Peng L, Turesky RJ. (2014). Optimizing proteolytic digestion conditions for the analysis of serum albumin adducts of 2-amino-1-methyl-6-phenylimidazo[4,5-b]pyridine, a potential human carcinogen formed in cooked meat. J Proteomics 103:267-278.

Puangsombat K, Gadgil P, Houser TA, Hunt MC, Smith JS. (2012). Occurrence of heterocyclic amines in cooked meat products. Meat Sci 90:739-746.

Rappaport SM, Li H, Grigoryan H, Funk WE, Williams ER. (2012). Adductomics: characterizing exposures to reactive electrophiles. Toxicol Lett 213:82-90.

Schut HAJ, Snyderwine EG. (1999). DNA adducts of heterocyclic amine food mutagens: implications for mutagenesis and carcinogenesis. Carcinogenesis 20:353-368.

Shirai T, Sano M, Tamano S, Takahashi S, Hirose M, Futakuchi M, et al. (1997). The prostate: a target for carcinogenicity of 2-amino-1-methyl-6-phenylimidazo[4,5-b]pyridine (PhIP) derived from cooked foods. Cancer Res 57:195- 198.

Sinha R, Knize MG, Salmon CP, Brown ED, Rhodes D, Felton JS, et al. (1998b). Heterocyclic amine content of pork products cooked by different methods and to varying degrees of doneness. Food Chem Toxicol 36:289-297. 
Sinha R, Rothman N, Salmon CP, Knize MG, Brown DE, Swanson CA, et al. (1998a). Heterocyclic amine content in beef cooked by different methods to varying degrees of doneness and gravy made from meat drippings. Food Chem Toxicol 36:279-287.

Sinha R. (2002). An epidemiologic approach to studying heterocyclic amines. Mutat Res-Fund Mol M 506-507:197-204.

Sugimura T, Wakabayashi K, Nakagama H, Nagao M. (2004). Heterocyclic amines:

Mutagens/carcinogens produced during cooking of meat and fish. Cancer Sci 95:290-299.

Tang D, Kryvenko ON, Wang Y, Trudeau S, Rundle A, Takahashi S, et al. (2013). 2-Amino-1-methyl-6phenylimidazo[4,5-b]pyridine (PhIP)-DNA adducts in benign prostate and subsequent risk for prostate cancer. Int J Cancer 133:961-971.

Turesky RJ, Guengerich FP, Guillouzo A, Langouet S. (2002). Metabolism of heterocyclic aromatic amines by human hepatocytes and cytochrome P4501A2. Mutat Res-Fund Mol M 506-507:187-195.

Turesky RJ, Le Marchand L. (2011). Metabolism and biomarkers of heterocyclic aromatic amines in molecular epidemiology studies: Lessons learned from aromatic amines. Chem Res Toxicol 24:11691214.

Turesky RJ, Skipper PL, Tannenbaum SR. (1987). Binding of 2-amino-3-methylimidazo[4,5-f]quinoline to hemoglobin and albumin in vivo in the rat. Identification of an adduct suitable for dosimetry.

Carcinogenesis 8:1537-1542.

US National Cancer Institute. CHARRED database [Online]: Computerized Heterocyclic Amines Resource for Research in Epidemiology of Disease. Available at:

http://dceg.cancer.gov/tools/design/charred Accessed on 23 April 2015.

Wang Y, Peng, L, Bellamre M, Langouet S, Turesky RJ. (2015). Mass spectrometric characterization of human serum albuminadducts formed with $\mathrm{N}$-oxidized metabolites of 2-amino-1-methylphenylimidazo[4,5-b]pyridine in human plasma and hepatocytes. Chem Res Toxicol DOI: 10.1021/acs.chemrestox.5b00075.

Zhang Y, Yu C, Mei J, Wang S. (2013). Formation and mitigation of heterocyclic aromatic amines in fried pork. Food Addit Contam A: Chem Anal Control Expo Risk Assess 30:1501-1507. 


\section{Highlights}

- Sensitive LC-MS/MS method validated for carcinogenic food-derived heterocyclic aromatic amines in plasma (LoD 1-5 pg/ml).

- Extensive range of hydrolysis procedures demonstrated HCAs released from plasma protein adducts in only 1 of 122 samples.

- Acid-labile HCAs adducted to blood proteins are not viable biomarkers of HCA dietary exposure.

- Search for HCA biomarkers should concentrate on stabilised HCA-peptide markers and emerging untargeted -omic approaches. 


\section{Tables}

Table 1. Acid (hydrochloric acid, $\mathrm{HCl}$ ) and alkaline (sodium hydroxide, $\mathrm{NaOH}$ ) hydrolysis conditions assessed for release of protein-adducted HCAs from human plasma pooled from high HCA intake participants.

\begin{tabular}{lllll}
\hline Acid / Alkali & Time $(\mathrm{h})$ & Temp. $\left({ }^{\circ} \mathrm{C}\right)$ & Reference & Reference target analytes \\
\hline $0.1 \mathrm{M} \mathrm{HCl}$ & 1 & 80 & Magagnotti et al., 2000 & PhIP/MelQx in vivo HSA/Hb adducts \\
$0.2 \mathrm{M} \mathrm{HCl}$ & 1 & 37 & Peng \& Turesky, 2011 & PhIP in vitro HSA adducts \\
$0.5 \mathrm{M} \mathrm{HCl}$ & 18 & 37 & Lynch et al., 1991 & MelQx in vitro Hb adducts \\
$2 \mathrm{M} \mathrm{HCl}$ & 1 & 80 & Busquets et al., 2006 & PhIP in vitro fortified Hb \\
$2 \mathrm{M} \mathrm{HCl}$ & 18 & 95 & Current study & $*$ \\
$6 \mathrm{M} \mathrm{HCl}$ & 2 & 80 & Current study & $*$ \\
$6 \mathrm{M} \mathrm{HCl}$ & 3 & 95 & Kataoka et al., 2010 & PhIP cooked meat/fish protein adducts \\
$0.5 \mathrm{M} \mathrm{NaOH}$ & 18 & 95 & Crosbie et al., 2000 & PhIP in vitro cell culture DNA adducts \\
$1 \mathrm{M} \mathrm{NaOH}$ & 2 & 80 & Bessette et al., 2009 & PhIP in vivo hair melanin adducts \\
\hline
\end{tabular}


Table 2. Heterocyclic aromatic amine LC-MS/MS fragmentation conditions.

\begin{tabular}{lllll}
\hline Analyte & $\mathrm{t}_{\mathrm{R}}(\mathrm{min})$ & Primary transition $(\mathrm{m} / \mathrm{z})$ & $\begin{array}{l}\text { Confirmatory } \\
\text { transition }(\mathrm{m} / \mathrm{z})\end{array}$ & Collision energy $(\mathrm{V})$ \\
\hline PhIP & 2.21 & $225.2>210.1$ & $225.2>183.2$ & $26 / 28$ \\
D3-PhIP & 2.21 & $228.2>210.1$ & $*$ & 28 \\
MelQx & 1.07 & $214.2>199.1$ & $214.2>131.1$ & $24 / 36$ \\
D3-MelQx & 1.07 & $217.1>199.2$ & $*$ & 26 \\
7,8-DiMelQx & 1.31 & $228.2>131.1$ & $228.2>213.1$ & $36 / 24$ \\
4,8-DiMelQx & 1.38 & $228.2>212.0$ & $228.2>213.1$ & $35 / 26$ \\
D3-4,8-DiMelQx & 1.38 & $231.2>213.1$ & $*$ & 24 \\
\hline
\end{tabular}


Table 3. Acid-labile heterocyclic aromatic amines incorporated into human proteins following in vitro incubation with human hepatic microsomes and exhaustive dialysis. HCAs were quantified by LCMS/MS following acid hydrolysis and liquid-liquid extraction.

\begin{tabular}{lll}
\hline HCA & Protein & ng HCA/mg protein \\
\hline PhIP & Albumin & 9.1 \\
PhIP & Haemoglobin & 23.5 \\
MelQx & Albumin & 7.9 \\
MelQx & Haemoglobin & 6.5 \\
\hline
\end{tabular}


Table 4. Assay validation parameters for the hydrolysis $\left(2 \mathrm{M} \mathrm{HCl}, 1 \mathrm{~h}, 80^{\circ} \mathrm{C}\right)$, extraction and quantification by LC-MS/MS of HCAs fortified in human plasma at $10 \mathrm{pg} / \mathrm{ml}$.

\begin{tabular}{lllll}
\hline & PhIP & MelQx & 7,8 -DiMelQx & 4,8-DiMelQx \\
\hline Mean recovery $(\%)^{\mathrm{a}}$ & 90.7 & 115.5 & 105.7 & 103.4 \\
Mean within day RSD $^{\mathrm{b}}(\%)$ & 6.7 & 8.8 & 4.2 & 4.7 \\
Between day RSD $(\%)$ & 7.9 & 8.8 & 6.8 & 5.0 \\
Limit of detection $(\mathrm{pg} / \mathrm{ml})$ & 5 & 2 & 1.5 & 1 \\
Limit of quantification $(\mathrm{pg} / \mathrm{ml})$ & 15 & 5 & 4 & 2 \\
\hline
\end{tabular}

${ }^{a}$ Internal standard corrected recovery, except for PhIP where d3-PhIP was omitted

${ }^{\mathrm{b}}$ Relative Standard Deviation 
Table 5. Cross-sectional study participants $(n=122)$ categorised in tertiles by total dietary HCA intake (ng/day) estimated from 7-day food diaries.

HCA tertile $1(n=41) \quad$ HCA tertile $2(n=40) \quad$ HCA tertile $3(n=41)$

\begin{tabular}{llll}
\hline Mean age (years, SD) & $32.8(9.5)$ & $34.0(13.4)$ & $30.1(10.9)$ \\
Male (n, \%) & $18(43.9)$ & $16(40.0)$ & $13(31.7)$ \\
Female (n, \%) & $23(56.1)$ & $24(60.0)$ & $28(68.3)$ \\
\multicolumn{1}{l}{ Mean HCA intake (ng/d, SD) } & & \\
MelQx & $29.3(30.0)$ & $102.2(55.8)$ & $201.8(104.9)$ \\
DiMelQx & $12.9(23.5)$ & $18.4(17.3)$ & $44.2(34.8)$ \\
PhIP & $53.6(50.1)$ & $344.4(135.9)$ & $912.0(349.9)$ \\
Total HCA & $95.8(70.6)$ & $464.9(149.8)$ & $1157.6(431.9)$ \\
\hline
\end{tabular}


Figure 1. ESI-LC-MS/MS MRM chromatograms of primary quantitation and secondary confirmatory peaks of four heterocyclic aromatic amines extracted from human plasma fortified at $5 \mathrm{pg} / \mathrm{ml}$. Samples were acid hydrolysed $\left(2 \mathrm{M} \mathrm{HCl}, 1 \mathrm{~h}, 80^{\circ} \mathrm{C}\right)$ and extracted with ethyl acetate and cation exchange SPE. Analyte names, $\mathrm{m} / \mathrm{z}$ transitions and peak heights are listed.
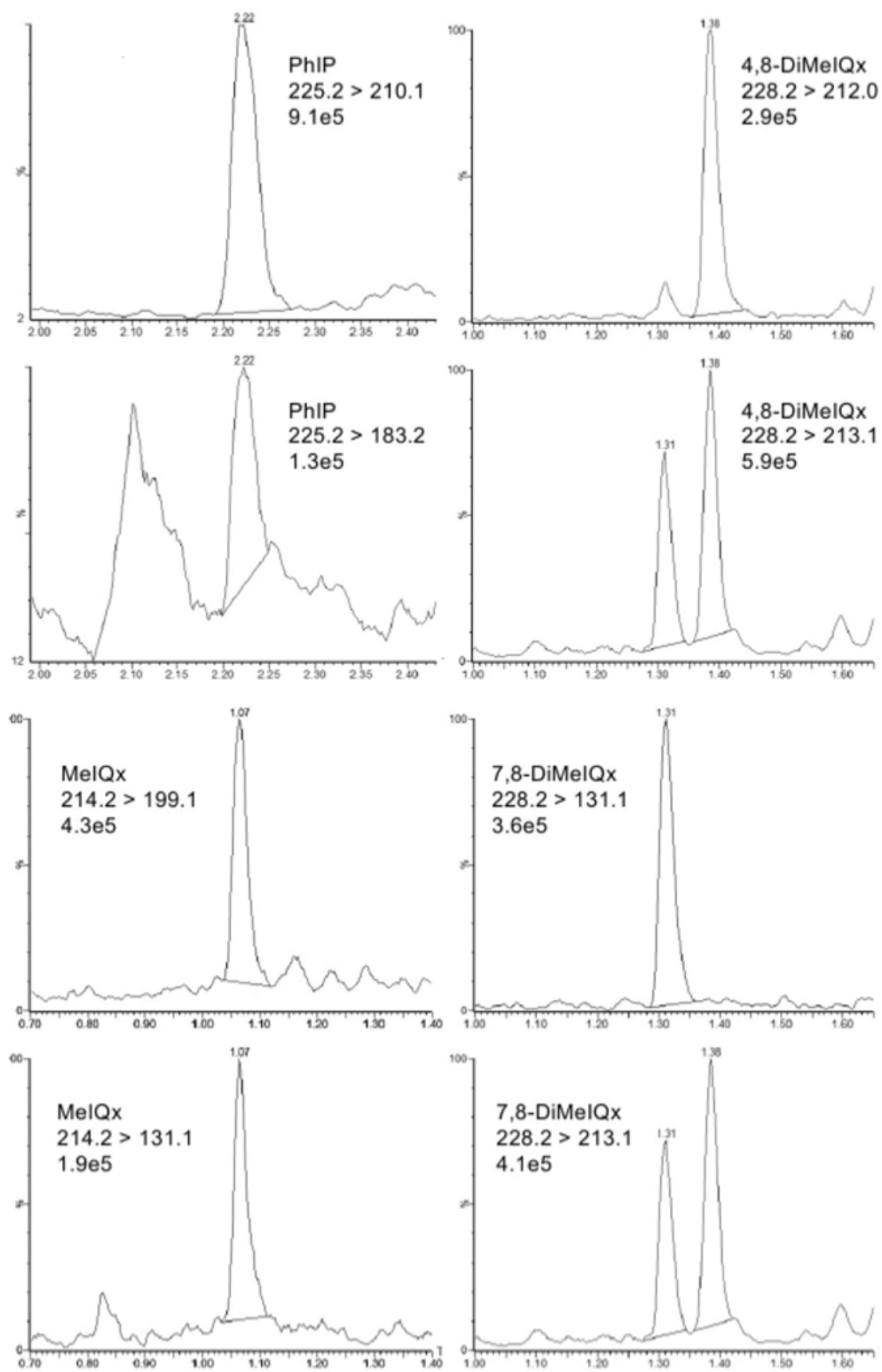